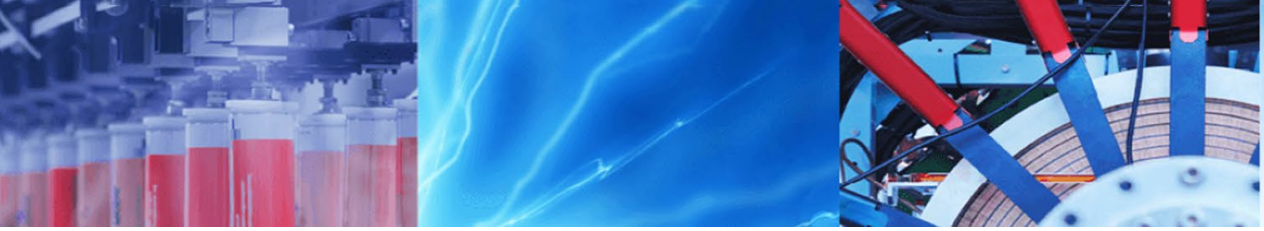

Research Article

\title{
(E)-Substituted- $\mathrm{N}-((1,3-$ diphenyl-1H-pyrazol-4-yl)methylene) benzeneamine: synthesis, characterization, antibacterial, and MTT assessment
}

\author{
Mohammad Arshad ${ }^{1}$ (1) $\cdot$ Mohd Shoeb Khan ${ }^{2} \cdot$ Shahab Ali Asghar Nami ${ }^{3} \cdot$ Dabeer Ahmad $^{4}$
}

(c) Springer Nature Switzerland AG 2019

\begin{abstract}
To find out some novel antimicrobial chemotherapeutic agents, fifteen (E)-Substituted-N-(1,3-diphenyl-1 H-pyrazol-4-yl) methylene)benzeneamine derivative (1-15) were synthesized. Structural elucidation of the prepared derivatives (1-15) was achieved by FTIR, NMR $\left({ }^{1} \mathrm{H}\right.$ or $\left.{ }^{13} \mathrm{C}\right)$, Mass spectroscopy and elemental analysis. After structural analyses the derivatives were subjected for biological assessment to estimate the antimicrobial therapeutic potential as well as the percent viability of the cells by disk diffusion methods and MTT assay. All the experiments were performed in triplicate; Ciprofloxacin and DMSO were used as positive and negative control. The results exhibited that the compounds 3, 4, 7-14 were found to exhibit significant antimicrobial therapeutic effect against all microorganisms, while some compounds of the series like $5,6,15$, possessed moderate and compound 1 was found less significant potential. The percent viability of the cells were observed in the range $91-96 \%$ at lowest concentration $3.125 \mu \mathrm{M}$ while $70-75 \%$ at the highest $100 \mu \mathrm{M}$.
\end{abstract}

Keywords Pyrazole derivatives · Antimicrobial and MTT assay

\section{Introduction}

The antimicrobial resistance (pathogens developed resistance to the available chemotherapeutic agents) has been a matter of great concern and reported the cause of 700,000 Deaths/Annum globally [1]. The pathogenic resistance has been a threat to the global community that once again become the major cause of the death due to the infectious disease [2]. To get rid off with this issue there is always requirement for the preparation of new chemotherapeutic agents to combat multi-drug resistant (MDR) strains. Pyrazole is one of the important heterocyclic nuclei in heterocyclic chemistry and represented various medicinal properties and a lot of research has been performed targeting this functional nucleus. Pyrazole moiety has been found in some currently used chemotherapeutic agents like Rimonabant, Tapoxalin, Lonazolac, Pyrazofurin, Epirizole, Celecoxib and Fezolamine etc. [3]. The versatile therapeutic application of the pyrazole derivative have been reported such as antimicrobial [4], Antimalarial [5], anticancer [6], anti-inflammatory [7], antidepressant [8], anticonvulsant [9], selective enzyme inhibitory activities [10], antipyretic [11], analgesic [12], fungicidal [13], fungistatic [14], antihyperglycemic [15], antiviral [16], antitumor [16], etc. On the other hand the derivatives with $\mathrm{HC}=\mathrm{N}$ functionality have been reported to exhibit many therapeutic effects like antibacterial, antifungal, antimicrobial, anticonvulsant, anti-HIV, and antitumor etc. [17-19].

Mohammad Arshad, mohdarshad1985@gmail.com | 'Department of Basic Sciences, College of Medicine, Al-Dawadmi, Shaqra University, Al-Dawadmi 11911, Saudi Arabia. ${ }^{2}$ Interdisciplinary Nanotechnology Centre, Aligarh Muslim University, Aligarh, India. ${ }^{3}$ Department of Kulliyat, Faculty of Unani Medicine, Aligarh Muslim University, Aligarh, India. ${ }^{4}$ College of Pharmacy, Al-Dawadmi, Shaqra University, Al-Dawadmi, Saudi Arabia.

SN Applied Sciences (2019) 1:548 | https://doi.org/10.1007/s42452-019-0571-8

Received: 20 February 2019 / Accepted: 6 May 2019 / Published online: 11 May 2019 


\section{Results and discussion}

Series of fifteen (E)-Substituted-N-((1,3-diphenyl$1 \mathrm{H}$-pyrazol-4-yl)methylene)benzeneamine derivative (1-15) was aimed for the synthesis, following the three step procedure (Fig. 1). The first step includes the formation of Schiff bases $\left(a_{1}-a_{5}\right)$ by the reaction in between phenylhydrazine and substituted ketones. In the second step the Schiff bases undergoes cyclization to yield pyrazole carboxaldehyde (b1-b5) nucleus by using dimethylformamide (DMF) and the desired compounds (1-15) by the condensation reaction between pyrazole carboxaldehyde (b1-b5) and substituted amines in ethanol and drop of acetic acid under reflux. The prepared derivatives (a1-a5), (b1-b5) and (1-15) were then analyzed for structural confirmation by variety of analytical techniques such as FTIR, NMR, Mass Spectroscopy, Elemental analysis. The FTIR bands around 1590-1602 and $3190-3222 \mathrm{~cm}^{-1}$ due to the presence of $\mathrm{C}=\mathrm{N}$ and $\mathrm{NH}$ functional groups confirmed the formation of compounds (a1-a5), the singlet around 1098-11.18 ppm in ${ }^{1} \mathrm{H}-\mathrm{NMR}$ spectra due to the $\mathrm{NH}$ proton and a strong signal around $166.08-166.90 \mathrm{ppm}$ in ${ }^{13} \mathrm{C}-\mathrm{NMR}$ spectra due to $\mathrm{C}=\mathrm{N}$ carbon further confirmed the formation of compounds (a1-a5). The appearance of bands around $1603-1619$ and $1718-1725 \mathrm{~cm}^{-1}$ in FTIR spectra due to the presence of $\mathrm{C}=\mathrm{N}$ and $\mathrm{C}=\mathrm{O}$ confirmed the synthesis of compounds (b1-b5). Further confirmation was achieved by ${ }^{1} \mathrm{H}-\mathrm{NMR}$ and ${ }^{13} \mathrm{C}$-NMR spectra, ${ }^{1} \mathrm{H}$-NMR spectra represented the singlet signals around 8.518-8.539 and 10.032-10.063 ppm due to Pyrazole Proton and $\mathrm{HC}=\mathrm{O}$ proton, the presence of carbon signals in ${ }^{13} \mathrm{C}-\mathrm{NMR}$ spectra around $106.59-188.91 \mathrm{ppm}$ and $186.89-190.20 \mathrm{ppm}$ due to pyrazole carbon and $\mathrm{HC}=\mathrm{O}$ carbon atom in the structure. The disappearance of the band in the FTIR

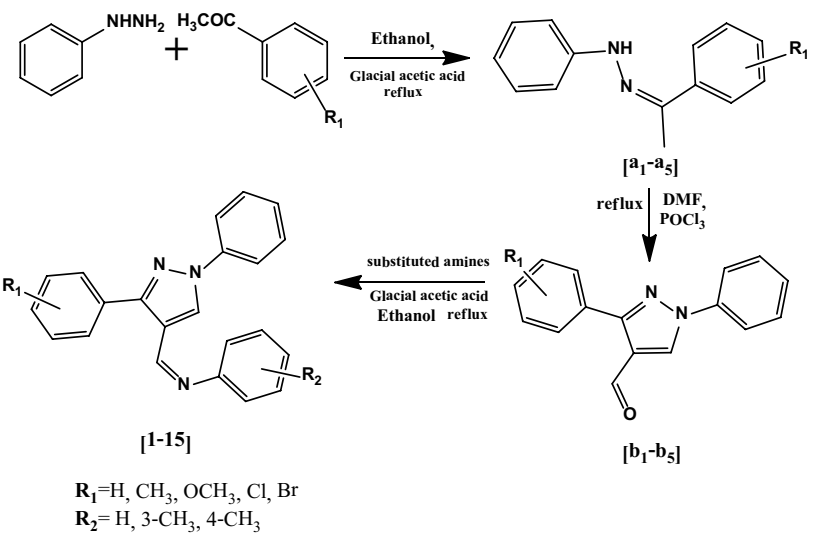

Fig. 1 Schematic Representation of the synthetic route adopted for the synthesis of pyrazole carbaldehyde and Schiff base derivatives spectra of the compounds (1-15) $1718-1725 \mathrm{~cm}^{-1}$ and the appearance of ne bands around $1609-1625 \mathrm{~cm}^{-1}$ due the formation of $\mathrm{HC}=\mathrm{N}$ functional group. Further confirmation of the structures was carried out by the ${ }^{1} \mathrm{H}-\mathrm{NMR}$ and ${ }^{13} \mathrm{C}-\mathrm{NMR}$ spectra, the ${ }^{1} \mathrm{H}$-NMR spectra exhibited the disappearance of the singlet around $10.032-10.063 \mathrm{ppm}$ due to the $\mathrm{HC}=\mathrm{O}$ proton and simultaneous appearance of the singlet around 8.109-8.381 ppm due to the $\mathrm{HC}=\mathrm{N}$ proton and ${ }^{13} \mathrm{C}-\mathrm{NMR}$ spectra portrayed the disappearance of the signal around $186.89-190.20 \mathrm{ppm}$ due to the $\mathrm{HC}=\mathrm{O}$ carbon, and the appearance of the signal around 151.09-153.67 due to the $\mathrm{HC}=\mathrm{N}$ carbon atom. Other signals were also observed around $114.24-116.01 \mathrm{ppm}$, $130.07-130.90$ and $150.20-152.89$ due to the three carbons of the pyrazole nucleus. Antimicrobial analysis of the compounds 1-15 was performed against the microbes [S. aureus (ATCC-25923), S. epidermidis (ATCC29887), E. coli (ATCC-25922), P. mirabilis (ATCC-25933) using the disc diffusion protocol in terms of zone of inhibition and minimum inhibitory concentration. The antimicrobial findings revealed that the compounds 3 , 4, 7-14 were found to exhibit very good activity against all microorganisms. While some compounds of the series like 5, 6, 15 possessed moderate and compound 1 was found less significant potential. The detailed results for zone of inhibition and MIC reported in Tables 1 and 2 . We also calculated the percent area of inhibition/ $\mu \mathrm{g}$ for all compounds and the results are represented in Fig. 2 .

Table 1 Antibacterial activity of pyrazole derivatives (1-15), Ciprofloxacin was used as positive control and negative control (DMSO) measured by the Holo Zone Test (Unit, $\mathrm{mm}$ )

\begin{tabular}{|c|c|c|c|c|}
\hline \multirow[t]{3}{*}{ Compounds } & \multicolumn{4}{|c|}{ Effect of Compounds on Microorganism } \\
\hline & \multicolumn{2}{|c|}{ Gram positive } & \multicolumn{2}{|c|}{ Gram negative } \\
\hline & S. aureus & S. epidermidis & E. coli & P. mirabilis \\
\hline 1 & $11.47 \pm .26$ & 10.29 & $12.36 \pm .31$ & $11.28 \pm .39$ \\
\hline 2 & $15.34 \pm 32$ & $17.97 \pm .57$ & $16.79 \pm .68$ & $14.72 \pm .68$ \\
\hline 3 & $20.52 \pm .56$ & $21.15 \pm .44$ & $21.88 \pm .50$ & $20.44 \pm .61$ \\
\hline 4 & $21.19 \pm .84$ & $22.31 \pm .62$ & $22.24 \pm .33$ & $20.70 \pm .99$ \\
\hline 5 & $17.93 \pm .57$ & $17.74 \pm .76$ & $15.71 \pm .06$ & $16.68 \pm .42$ \\
\hline 6 & $16.60 \pm .81$ & $18.74 \pm .55$ & $19.48 \pm .34$ & $18.13 \pm .44$ \\
\hline 7 & $21.80 \pm .36$ & $20.72 \pm .43$ & $22.74 \pm .27$ & $21.60 \pm .30$ \\
\hline 8 & $20.93 \pm .78$ & $22.66 \pm .68$ & $22.68 \pm .39$ & $21.62 \pm .35$ \\
\hline 9 & $20.23 \pm .53$ & $22.47 \pm .24$ & $23.44 \pm .11$ & $21.31 \pm .22$ \\
\hline 10 & $21.47 \pm .41$ & $21.06 \pm .26$ & $23.64 \pm .28$ & $21.36 \pm .043$ \\
\hline 11 & $21.71 \pm .37$ & $21.06 \pm .09$ & $23.76 \pm .39$ & $21.66 \pm .44$ \\
\hline 12 & $21.54 \pm .20$ & $22.85 \pm .17$ & $23.73 \pm .51$ & $21.92 \pm .47$ \\
\hline 13 & $21.72 \pm .46$ & $20.64 \pm .79$ & $19.76 \pm .25$ & $19.15 \pm .18$ \\
\hline 14 & $20.27 \pm .35$ & $21.88 \pm .66$ & $20.51 \pm .36$ & $22.28 \pm .30$ \\
\hline 15 & $19.41 \pm .45$ & $18.56 \pm .46$ & $18.71 \pm .25$ & $18.47 \pm .49$ \\
\hline Ciprofloxacin & 21.46 & $22.64 \pm .54$ & $23.82 \pm .47$ & $22.24 \pm .30$ \\
\hline
\end{tabular}


Table 2 Minimum inhibitory concentration $(\boldsymbol{\mu g} / \mathbf{m L})$ of pyrazole derivatives (1-15), Ciprofloxacin was used as positive control and negative control (DMSO) measured by the Holo Zone Test (Unit, $\mathrm{mm})$

\begin{tabular}{|c|c|c|c|c|}
\hline \multirow[t]{3}{*}{ Comp. no. } & \multicolumn{4}{|c|}{ Minimum inhibitory concentration, $\mu \mathrm{g} / \mathrm{Ml}$} \\
\hline & \multicolumn{2}{|c|}{ Gram positive } & \multicolumn{2}{|c|}{ Gram negative } \\
\hline & S. aureus & S. epidermidis & P. mirabilis & E. Coli \\
\hline 1 & 6.25 & 6.25 & 6.25 & 12.5 \\
\hline 2 & 6.25 & 6.25 & 6.25 & 12.5 \\
\hline 3 & 6.25 & 3.12 & 6.25 & 12.5 \\
\hline 4 & 6.25 & 3.12 & 6.25 & 12.5 \\
\hline 5 & 12.5 & 3.12 & 6.25 & 12.5 \\
\hline 6 & 6.25 & 6.25 & 6.25 & 12.5 \\
\hline 7 & 6.25 & 3.12 & 6.25 & 12.5 \\
\hline 8 & 6.25 & 3.12 & 6.25 & 12.5 \\
\hline 9 & 6.25 & 3.12 & 12.5 & 12.5 \\
\hline 10 & 6.25 & 3.12 & 12.5 & 12.5 \\
\hline 11 & 6.25 & 3.12 & 12.5 & 12.5 \\
\hline 12 & 6.25 & 3.12 & 6.25 & 12.5 \\
\hline 13 & 6.25 & 3.12 & 6.25 & 12.5 \\
\hline 14 & 6.25 & 3.12 & 6.25 & 12.5 \\
\hline 15 & 6.25 & 3.12 & 12.5 & 12.5 \\
\hline Ciprofloxacin & 6.25 & 3.12 & 6.25 & 12.5 \\
\hline
\end{tabular}

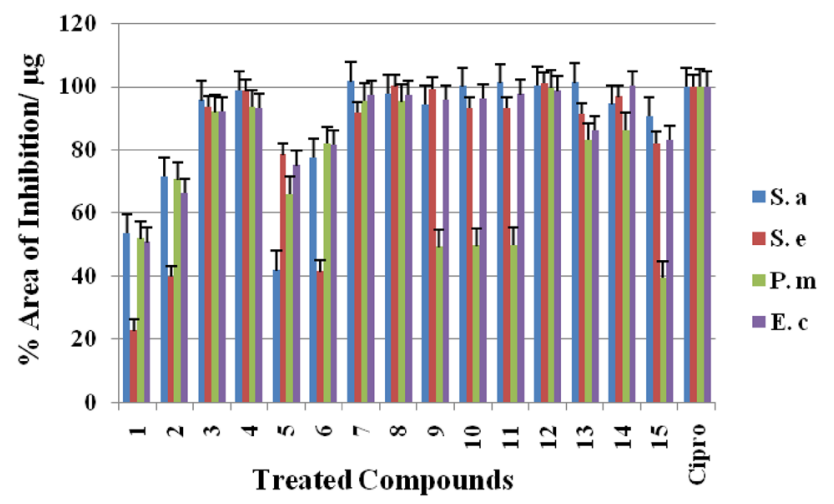

Fig. 2 Representing the percent area of inhibition/ $\mu \mathrm{g}$ of the pyrazole derivatives (1-15), and Ciprofloxacin

The synthesized compounds were then assessed for MTT assay to observe the percent viability of the cells using Hep G2 cells. The results of MTT assay portrayed that the percent viability of the cells was found to be concentration dependent. All the compounds possessed the percent viability of the cells in the range $91-96 \%$ at $3.125 \mu \mathrm{M}$ and while on increasing concentration up to $100 \mu \mathrm{M}$, the percent viability of the cells were found $70-75 \%$ at $100 \mu \mathrm{M}$. the detailed MTT assay results are represented in Fig. 3.

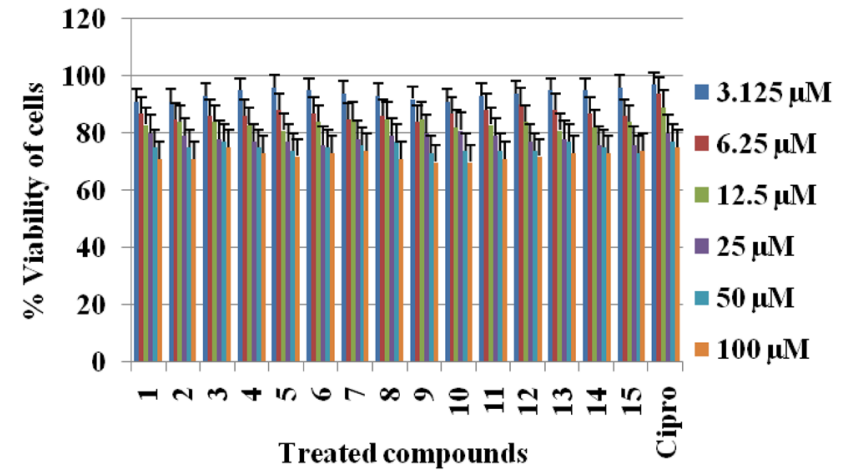

Fig. 3 Representing the percent viability of cells (Hep G2), on treatment with pyrazole derivatives (1-15), and Ciprofloxacin

\section{Experimental}

\subsection{Chemistry}

\subsubsection{General procedure for the synthesis of compounds $a_{1}-a_{5}$}

To a $100 \mathrm{~mL}$ round bottom flask was added an appropriate ketone $(10 \mathrm{mmol})$, phenylhydrazine $(10 \mathrm{mmol})$, few drops of glacial acetic acid and $50 \mathrm{~mL}$ absolute ethanol. The reaction mixture was refluxed at $80^{\circ} \mathrm{C}$. Completion of reaction was monitored by TLC, solid precipitate was obtained, filtered, dried and recrystallized from ethanol.

[a ${ }_{1}$ (2E)-1-phenyl-2-(1-phenylethylidene)hydrazine Yield: $88 \%$; mp: ${ }^{\circ} \mathrm{C}$; yellow crystals; Anal. calc. for $\mathrm{C}_{14} \mathrm{H}_{14} \mathrm{~N}_{2}$ : C 79.97\%, H 6.71\%, N 13.32\%, found: C 78.20\%, $\mathrm{H}$ 6.72\%, N 13.30\%; IR v $v_{\max }\left(\mathrm{cm}^{-1}\right): 1595(\mathrm{C}=\mathrm{N}), 3012(\mathrm{CH}-$ $\mathrm{Ar}), 3220(\mathrm{NH}) ;{ }^{1} \mathrm{H}$ NMR $\left(\mathrm{CDCl}_{3}\right) \delta(\mathrm{ppm}): 1.12\left(\mathrm{~s}, 3 \mathrm{H}, \mathrm{CH}_{3}\right)$, 7.28-7.58 (m, Ar-H), $11.08(\mathrm{~s}, 1 \mathrm{H}, \mathrm{NH}) ;{ }^{13} \mathrm{C} \mathrm{NMR}\left(\mathrm{CDCl}_{3}\right)$ Sppm: $14.12\left(\mathrm{CH}_{3}\right), 116.10,118.12,128.24,129.02,130.20$, 131.60, $166.90(\mathrm{C}=\mathrm{N})$; $\mathrm{ESI}-\mathrm{MS}(\mathrm{m} / \mathrm{z}):\left[\mathrm{M}^{+}+1\right] 210.28$.

[a $a_{2}$ (E)-1-phenyl-2-(1-(p-tolylethylidene)hdrazine Yield: $86 \%$; mp: ${ }^{\circ} \mathrm{C}$; yellow crystals; Anal. calc. for $\mathrm{C}_{15} \mathrm{H}_{16} \mathrm{~N}_{2}$ : C 80.32\%, H 7.19\%, N 12.49\%, found: C 80.28\%, $\mathrm{H} 7.20 \%, \mathrm{~N} 12.52 \%$; IR $v_{\max }\left(\mathrm{cm}^{-1}\right): 1590(\mathrm{C}=\mathrm{N}), 3018(\mathrm{CH}-$ $\mathrm{Ar}), 3206(\mathrm{NH}) ;{ }^{1} \mathrm{H}$ NMR $\left(\mathrm{CDCl}_{3}\right) \delta(\mathrm{ppm}): 1.02\left(\mathrm{~s}, 3 \mathrm{H}, \mathrm{CH}_{3}\right)$, $2.20\left(\mathrm{~s}, 3 \mathrm{H}, \mathrm{CH}_{3}\right), 7.01-7.50(\mathrm{~m}, \mathrm{Ar}-\mathrm{H}), 10.98(\mathrm{~s}, 1 \mathrm{H}, \mathrm{NH}) ;{ }^{13} \mathrm{C}$ NMR $\left(\mathrm{CDCl}_{3}\right)$ \&ppm: $13.90\left(\mathrm{CH}_{3}\right), 25.45\left(\mathrm{CH}_{3}\right) 116.42,118.88$, 128.22, 129.32, 130.10, 131.24, $166.42(\mathrm{C}=\mathrm{N})$; $\mathrm{ESI}-\mathrm{MS}(\mathrm{m} / \mathrm{z})$ : $\left[\mathrm{M}^{+}+1\right] 224.12$.

[ $\left.a_{3}\right]$ (E)-2-(1-(4-methoxyphenylethylidene)-1-phenylhdrazine Yield: $88 \%$; mp: ${ }^{\circ} \mathrm{C}$; creamy yellow crystals; Anal. calc. for $\mathrm{C}_{15} \mathrm{H}_{16} \mathrm{~N}_{2} \mathrm{O}: \mathrm{C} 74.97 \%, \mathrm{H} 6.71 \%, \mathrm{~N} 11.66 \%$, found: C 74.88\%, H 6.72\%, N 11.66\%; IR v max $\left(\mathrm{cm}^{-1}\right): 1596(\mathrm{C}=\mathrm{N})$, 3005 (CH-Ar), $3190(\mathrm{NH}) ;{ }^{1} \mathrm{H}$ NMR $\left(\mathrm{CDCl}_{3}\right) \delta(\mathrm{ppm}): 1.06$ (s, 
$\left.3 \mathrm{H}, \mathrm{CH}_{3}\right), 3.80\left(\mathrm{OCH}_{3}\right) 6.82-7.52(\mathrm{~m}, \mathrm{Ar}-\mathrm{H}), 11.10(\mathrm{~s}, 1 \mathrm{H}, \mathrm{NH})$;

${ }^{13} \mathrm{C} \mathrm{NMR}\left(\mathrm{CDCl}_{3}\right)$ dppm: $14.22\left(\mathrm{CH}_{3}\right), 56.5\left(\mathrm{OCH}_{3}\right)$ 116.40, $118.32,128.12,129.54,130.25,131.43,161.22$ (CO), 166.08 $(\mathrm{C}=\mathrm{N}) ; \mathrm{ESI}-\mathrm{MS}(\mathrm{m} / \mathrm{z}):\left[\mathrm{M}^{+}+1\right] 240.10$.

[a $\left.{ }_{4}\right]$ (E)-2-[1-(4-chlorophenyl)ethylidene]-1-phenylhdrazine Yield: $84 \%$; $\mathrm{mp}:{ }^{\circ} \mathrm{C}$; white crystals; Anal. calc. for $\mathrm{C}_{14} \mathrm{H}_{13} \mathrm{ClN}_{2}: \mathrm{C} 68.71 \%, \mathrm{H}$ 5.35\%, N $11.45 \%$, found: C $68.72 \%$, $\mathrm{H} 5.38 \%, \mathrm{~N} 11.52 \%$; IR $v_{\max }\left(\mathrm{cm}^{-1}\right): 1602(\mathrm{C}=\mathrm{N}), 3010(\mathrm{CH}-$ $\mathrm{Ar}), 3222(\mathrm{NH}) ;{ }^{1} \mathrm{H} \mathrm{NMR}\left(\mathrm{CDCl}_{3}\right) \delta(\mathrm{ppm}): 1.06\left(\mathrm{~s}, 3 \mathrm{H}, \mathrm{CH}_{3}\right)$, 6.46-7.62 (m, Ar-H), $11.18(\mathrm{~s}, 1 \mathrm{H}, \mathrm{NH}) ;{ }^{13} \mathrm{C} \mathrm{NMR}\left(\mathrm{CDCl}_{3}\right)$ Sppm: $14.52\left(\mathrm{CH}_{3}\right), 116.11,118.02,128.23,129.65,130.09$, 131.22, $166.66(\mathrm{C}=\mathrm{N})$; $\mathrm{ESI}-\mathrm{MS}(\mathrm{m} / \mathrm{z}):\left[\mathrm{M}^{+}+1\right] 244.10$.

[a $\left.{ }_{5 x}\right]$ (E)-2-[1-(4-bromophenyl)ethylidene]-1-phenylhdrazine Yield: $92 \%$; $\mathrm{mp}:{ }^{\circ} \mathrm{C}$; yellow crystals; Anal. calc. for $\mathrm{C}_{14} \mathrm{H}_{13} \mathrm{BrN}_{2}: \mathrm{C} 58.15 \%, \mathrm{H} 4.53 \%$, N 9.69\%, found: C 58.20\%, $\mathrm{H} 4.50 \%, \mathrm{~N}$ 9.72\%; IR $v_{\max }\left(\mathrm{cm}^{-1}\right): 1600(\mathrm{C}=\mathrm{N}), 3014(\mathrm{CH}-\mathrm{Ar})$, $3202(\mathrm{NH}) ;{ }^{1} \mathrm{H} \mathrm{NMR}\left(\mathrm{CDCl}_{3}\right) \delta(\mathrm{ppm}): 1.16\left(\mathrm{~s}, 3 \mathrm{H}, \mathrm{CH}_{3}\right), 6.52-$ $7.56(\mathrm{~m}, \mathrm{Ar}-\mathrm{H}), 11.12(\mathrm{~s}, 1 \mathrm{H}, \mathrm{NH}) ;{ }^{13} \mathrm{C}$ NMR $\left(\mathrm{CDCl}_{3}\right) \delta \mathrm{ppm}$ : $13.8\left(\mathrm{CH}_{3}\right), 116.06,118.32,128.12,129.07,130.63,131.63$, $166.48(\mathrm{C}=\mathrm{N})$; $\mathrm{ESI}-\mathrm{MS}(\mathrm{m} / \mathrm{z}):\left[\mathrm{M}^{+}+1\right] 288.05$.

\subsubsection{General procedure for the synthesis of compound $b_{1}-b_{5}$}

Phosphorous oxychloride ( $25 \mathrm{mmol}$ ) was added to DMF $(100 \mathrm{~mL})$ at $0{ }^{\circ} \mathrm{C}$ and stirred for $30 \mathrm{~min}$. Compound $\mathbf{a}_{\mathbf{1}}-\mathbf{a}_{\mathbf{5}}$ $(10 \mathrm{mmol})$ was added slowly to this mixture and stirred for $5 \mathrm{~h}$. The crude reaction mixture was then quenched into water $(1 \mathrm{~L})$ and stirred for an additional $1 \mathrm{~h}$ and extracted with ethyl acetate. The organic layer was separated, washed with water, dried and evaporated under reduced pressure. The crude was recrystallized from ethanol.

[b $b_{1}$ 1,3-diphenyl-1H-pyrazole-4-carbaldehyde Yield: 95\%; mp: $218-220^{\circ} \mathrm{C}$; yellowish crystals; Anal. calc. for $\mathrm{C}_{16} \mathrm{H}_{12} \mathrm{~N}_{2} \mathrm{O}: \mathrm{C} 77.40 \%, \mathrm{H} 4.87 \%, \mathrm{~N} 11.28 \%$, found: C 77.92\%, $\mathrm{H} 5.10 \%, \mathrm{~N} 11.18 \%$; IR $v_{\max }\left(\mathrm{cm}^{-1}\right): 1603(\mathrm{C}=\mathrm{N}), 1719(\mathrm{C}=\mathrm{O})$, $3022(\mathrm{CH}-\mathrm{Ar}) ;{ }^{1} \mathrm{H}-\mathrm{NMR}\left(\mathrm{CDCl}_{3}\right) \delta(\mathrm{ppm}): 7.260-7.647(\mathrm{~m}$, Ar-H), 7.792-7.944 (m, Ar-H), $8.532(\mathrm{~s}, 1 \mathrm{H}, \mathrm{CH}$, pyrazole ring), $10.062(\mathrm{~s}, 1 \mathrm{H}, \mathrm{HC}=0) ;{ }^{13} \mathrm{C}-\mathrm{NMR}\left(\mathrm{CDCl}_{3}\right) \delta \mathrm{ppm}: 107.19$ (1C-pyrazole ring), 120.57, 127.03, 127.68, 229.31, 129.92, 135.93 (1C-pyrazole ring), 139.75, 151.03 (1C pyrazole ring), $189.20(\mathrm{HC}=\mathrm{O})$; $\mathrm{ESI}-\mathrm{MS}(\mathrm{m} / \mathrm{z}):\left[\mathrm{M}^{+}+1\right] 248.11$.

[b $b_{2 x}$ ] 1-phenyl-3-p-tolyl-1H-pyrazole-4-carbaldehyde Yield: $95 \%$; mp: $198-200{ }^{\circ} \mathrm{C}$; white crystals; Anal. calc. for $\mathrm{C}_{17} \mathrm{H}_{14} \mathrm{~N}_{2} \mathrm{O}$ : C 77.84\%, H 5.38\%, N 10.68\%; found: C 77.79\%, H 5.42\%, N 10.65\%; IR $v_{\max }\left(\mathrm{cm}^{-1}\right): 1619(\mathrm{C}=\mathrm{N}), 1723$ $(\mathrm{C}=\mathrm{O}), 3022(\mathrm{CH}-\mathrm{Ar}) ;{ }^{1} \mathrm{H}-\mathrm{NMR}\left(\mathrm{CDCl}_{3}\right) \delta(\mathrm{ppm}): 2.388(\mathrm{~s}, 3 \mathrm{H}$, $\left.\mathrm{CH}_{3}\right), 7.259-7.413(\mathrm{~m}, \mathrm{Ar}-\mathrm{H}), 7.485-7.537(\mathrm{~m}, \mathrm{Ar}-\mathrm{H}), 7.702$ $(\mathrm{d}, 1 \mathrm{H}, \mathrm{Ar}-\mathrm{H}), 7.781(\mathrm{~d}, 1 \mathrm{H}, \mathrm{Ar}-\mathrm{H}), 8.539(\mathrm{~s}, 1 \mathrm{H}, \mathrm{CH}$, pyrazole ring), $10.051(\mathrm{~s}, 1 \mathrm{H}, \mathrm{HC}=0) ;{ }^{13} \mathrm{C}-\mathrm{NMR}\left(\mathrm{CDCl}_{3}\right)$ Sppm: 21.39 $\left(\mathrm{CH}_{3}\right), 107.44$ (1C-pyrazole ring), 120.35, 127.64, 127.81, 229.74, 129.76, 135.89 (1C-pyrazole ring), 139.70, 151.23 (1C-pyrazole ring), $188.91(\mathrm{HC}=\mathrm{O}) ; \mathrm{ESI}-\mathrm{MS}(\mathrm{m} / \mathrm{z}):\left[\mathrm{M}^{+}+1\right]$ 262.13.

[b $b_{3}$ 3-(4-methoxyphenyl)-1-phenyl-1H-pyrazole-4-carbaldehyde Yield: $95 \%$; $\mathrm{mp}: 210-212{ }^{\circ} \mathrm{C}$; creamy white crystals; Anal. calc. for $\mathrm{C}_{187} \mathrm{H}_{14} \mathrm{~N}_{2} \mathrm{O}_{2}: \mathrm{C} 73.37 \%, \mathrm{H} 5.07 \%, \mathrm{~N}$ 10.07\%; found: C 73.39\%, H 5.11\%, N 10.04\%; IR v $v_{\max }\left(\mathrm{cm}^{-1}\right)$ : $1611(\mathrm{C}=\mathrm{N}), 1729(\mathrm{C}=\mathrm{O}), 3032(\mathrm{CH}-\mathrm{Ar}){ }^{1}{ }^{1} \mathrm{H}-\mathrm{NMR}\left(\mathrm{CDCl}_{3}\right) \delta$ (ppm): $3.875\left(\mathrm{~s}, 3 \mathrm{H}, \mathrm{OCH}_{3}\right) 7.014-7.532(\mathrm{~m}, \mathrm{Ar}-\mathrm{H}), 7.777-$ $7.807(\mathrm{~m}, \mathrm{Ar}-\mathrm{H}), 8.518(\mathrm{~s}, 1 \mathrm{H}, \mathrm{CH}$, pyrazole ring), $10.032(\mathrm{~s}$, $1 \mathrm{H}, \mathrm{HC}=\mathrm{O}) ;{ }^{13} \mathrm{C}-\mathrm{NMR}\left(\mathrm{CDCl}_{3}\right) \delta$ ppm: $56.71\left(\mathrm{OCH}_{3}\right), 107.58$ (1C-pyrazole ring), 120.75, 127.22, 127.91, 229.53, 129.76, 135.85 (1C-pyrazole ring), 139.25, 151.19 (1C-pyrazole ring), 190.20 (HC=O); $\mathrm{ESI}-\mathrm{MS}(\mathrm{m} / \mathrm{z}):\left[\mathrm{M}^{+}+1\right] 278.35$.

[ $b_{4}$ ] 3-(4-chlorophenyl)-1-phenyl-1H-pyrazole-4-carbaldehyde Yield: $95 \%$; mp: $220-222{ }^{\circ} \mathrm{C}$; white crystals; Anal. calc. for $\mathrm{C}_{16} \mathrm{H}_{11} \mathrm{ClN}_{2} \mathrm{O}$ : C 67.97\%, H 3.92\%, N 9.91\%; found: C 68.02\%, H 3.88\%, N 9.88\%; IR v $v_{\max }\left(\mathrm{cm}^{-1}\right)$ : 1609 $(\mathrm{C}=\mathrm{N}), 1719(\mathrm{C}=\mathrm{O}), 3025(\mathrm{CH}-\mathrm{Ar}) ;{ }^{1} \mathrm{H}-\mathrm{NMR}\left(\mathrm{CDCl}_{3}\right) \delta(\mathrm{ppm})$ : 7.261-7.549 (m, Ar-H), 7.773-7.848 (m, Ar-H), $8.537(\mathrm{~s}$, $1 \mathrm{H}, \mathrm{CH}$, pyrazole ring), $10.063(\mathrm{~s}, 1 \mathrm{H}, \mathrm{HC}=\mathrm{O}) ;{ }^{13} \mathrm{C}-\mathrm{NMR}$ $\left(\mathrm{CDCl}_{3}\right)$ Sppm: 106.59 (1C-pyrazole ring), 120.87, 127.59, 127.69, 229.78, 129.38, 135.56 (1C-pyrazole ring), 139.68, 151.11 (1C-pyrazole ring), 190.11 (HC=O); ESI-MS(m/z): $\left[\mathrm{M}^{+}+1\right] 282.70$.

[b $b_{5}$ 3-(4-bromophenyl)-1-phenyl-1-H-pyrazole-4-carbaldehyde Yield: $95 \%$; mp: $202-204{ }^{\circ} \mathrm{C}$; white crystals; Anal. calc. for $\mathrm{C}_{16} \mathrm{H}_{11} \mathrm{BrN}_{2} \mathrm{O}$ : C 58.74\%, H 3.39\%, N 8.56\%; found: C 59.07\%, H 3.42\%, N 8.80\%; IR v $v_{\max }\left(\mathrm{cm}^{-1}\right): 1611$ $(\mathrm{C}=\mathrm{N}), 1725(\mathrm{C}=\mathrm{O}), 3025(\mathrm{CH}-\mathrm{Ar}){ }^{1}{ }^{1} \mathrm{H}-\mathrm{NMR}\left(\mathrm{CDCl}_{3}\right) \delta(\mathrm{ppm})$ : 7.260-7.645 (m, Ar-H), 7.755-7.796 (m, Ar-H), $8.533(\mathrm{~s}, 1 \mathrm{H}$, $\mathrm{CH}$, pyrazole ring), $10.036(\mathrm{~s}, 1 \mathrm{H}, \mathrm{HC}=\mathrm{O}) ;{ }^{13} \mathrm{C}-\mathrm{NMR}\left(\mathrm{CDCl}_{3}\right)$ Sppm: 109.21 (1C-pyrazole ring), 120.75, 127.54, 127.75, 229.63, 129.68, 135.76 (1C-pyrazole ring), 139.57, 151.53 (1C-pyrazole ring), $186.89(\mathrm{HC}=\mathrm{O}) ; \mathrm{ESI}-\mathrm{MS}(\mathrm{m} / \mathrm{z}):\left[\mathrm{M}^{+}+1\right]$ 326.03.

\subsubsection{General procedure for the synthesis of compound 1-15}

To an appropriate aldehyde substituted aromatic amines was added in ethanol. Few drops of glacial acetic acid was also added and refluxed at $80^{\circ} \mathrm{C}$. Precipitate was obtained, filtered, dried and recrystallized from ethanol [19].

(E)-N-((1,3-diphenyl-1H-pyrazol-4-yl)methylene)benzeneamine Yield: $95 \%$; $\mathrm{mp}$ : $228-230{ }^{\circ} \mathrm{C}$; white crystals; Anal. calc. for $\mathrm{C}_{22} \mathrm{H}_{17} \mathrm{~N}_{3}$ : C 81.71\%, H 5.30\%, N 12.99\%; 
found: C 81.62\%, H 5.32\%, N 13.01\%; IR v $v_{\max }\left(\mathrm{cm}^{-1}\right): 1611$ $(\mathrm{C}=\mathrm{N}), 3025(\mathrm{CH}-\mathrm{Ar}) ;{ }^{1} \mathrm{H}-\mathrm{NMR}\left(\mathrm{CDCl}_{3}\right) \delta(\mathrm{ppm}): 6.683-6.978$ ( $\mathrm{m}, 5 \mathrm{H}, \mathrm{Ar}-\mathrm{H}), 7.082-7.222(\mathrm{~m}, 5 \mathrm{H}, \mathrm{Ar}-\mathrm{H}), 7.368-7.498(\mathrm{~m}$, $5 \mathrm{H}, \mathrm{Ar}-\mathrm{H}), 8.215(\mathrm{~s}, 1 \mathrm{H}, \mathrm{HC}=\mathrm{N}), 8.314(\mathrm{~s}, 1 \mathrm{H}, \mathrm{CH}$, pyrazole ring); ${ }^{13} \mathrm{C}-\mathrm{NMR}\left(\mathrm{CDCl}_{3}\right)$ Sppm: 114.90 (1C-pyrazole ring), $119.79,120.82,127.43,129.5571,129.58,130.70$ (1C-pyrazole ring), 136.81, 139.35, 150.59 (1C-pyrazoline ring), $153.67(\mathrm{HC}=\mathrm{N})$; $\mathrm{ESI}-\mathrm{MS}(\mathrm{m} / \mathrm{z}):\left[\mathrm{M}^{+}+1\right] 323.15$.

(E)-3-methyl-N-((1,3-diphenyl-1H-pyrazol-4-yl)methylene)benzeneamine Yield: $95 \%$; $\mathrm{mp}: 236-238^{\circ} \mathrm{C}$; white crystals; Anal. calc. for $\mathrm{C}_{23} \mathrm{H}_{19} \mathrm{~N}_{3}$ : $\mathrm{C} 81.87 \%, \mathrm{H} 5.68 \%, \mathrm{~N}$ 12.45\%; found: C 81.91\%, H 5.62\%, N 12.47\%; IR v $\max \left(\mathrm{cm}^{-1}\right)$ : $1619(\mathrm{C}=\mathrm{N}), 3025(\mathrm{CH}-\mathrm{Ar}) ;{ }^{1} \mathrm{H}-\mathrm{NMR}\left(\mathrm{CDCl}_{3}\right) \delta(\mathrm{ppm}): 2.359$ $\left(\mathrm{s}, 3 \mathrm{H}, \mathrm{CH}_{3}\right), 6.711-6.957(\mathrm{~m}, 5 \mathrm{H}, \mathrm{Ar}-\mathrm{H}), 7.097-7.215(\mathrm{~m}$, $5 \mathrm{H}, \mathrm{Ar}-\mathrm{H}), 7.310(\mathrm{~d}, 1 \mathrm{H}, \mathrm{Ar}-\mathrm{H}), 7.385-7.483(\mathrm{~m}, 3 \mathrm{H}, \mathrm{Ar}-\mathrm{H})$, $8.224(\mathrm{HC}=\mathrm{N}), 8.561(\mathrm{~s}, 1 \mathrm{H}, \mathrm{Ar}-\mathrm{H}), 8.612(\mathrm{~s}, 1 \mathrm{H}, \mathrm{CH}$, pyrazole ring); ${ }^{13} \mathrm{C}-\mathrm{NMR}\left(\mathrm{CDCl}_{3}\right)$ \&ppm: $22.01\left(\mathrm{CH}_{3}\right), 114.46$ (1C-pyrazole ring), 119.89, 120.77, 127.64, 129.55, 129.76, 130.90 (1C-pyrazole ring), 136.73, 139.60, 150.90 (1C-pyrazoline ring), $152.80(\mathrm{HC}=\mathrm{N})$; $\mathrm{ESI}-\mathrm{MS}(\mathrm{m} / \mathrm{z}):\left[\mathrm{M}^{+}+1\right] 337.14$.

(E)-4-methyl-N-((1,3-diphenyl-1H-pyrazol-4-yl)methylene)benzeneamine Yield: $95 \%$; $\mathrm{mp}: 232-234^{\circ} \mathrm{C}$; yellow crystals; Anal. calc. for $\mathrm{C}_{23} \mathrm{H}_{19} \mathrm{~N}_{3}: \mathrm{C} 81.87 \%, \mathrm{H} 5.68 \%, \mathrm{~N}$ 12.45\%; found: C 81.80\%, H 5.71\%, N 12.43\%; IR v $v_{\max }\left(\mathrm{cm}^{-1}\right)$ : $1616(\mathrm{C}=\mathrm{N}), 3025(\mathrm{CH}-\mathrm{Ar}) ;{ }^{1} \mathrm{H}-\mathrm{NMR}\left(\mathrm{CDCl}_{3}\right) \delta(\mathrm{ppm}): 2.367$ $\left(\mathrm{s}, 3 \mathrm{H}, \mathrm{CH}_{3}\right), 6.790-6.981(\mathrm{~m}, 5 \mathrm{H}, \mathrm{Ar}-\mathrm{H}), 7.093-7.195(\mathrm{~m}$, $5 \mathrm{H}, \mathrm{Ar}-\mathrm{H}), 7.219-7.343(\mathrm{~m}, 2 \mathrm{H}, \mathrm{Ar}-\mathrm{H}), 7.431-7.453(\mathrm{~m}, 2 \mathrm{H}$, $\mathrm{Ar}-\mathrm{H}), 8.381(\mathrm{HC}=\mathrm{N}), 8.502\left(\mathrm{~s}, 1 \mathrm{H}, \mathrm{CH}\right.$, pyrazole ring); ${ }^{13} \mathrm{C}-$ $\operatorname{NMR}\left(\mathrm{CDCl}_{3}\right)$ Sppm: $20.99\left(\mathrm{CH}_{3}\right), 114.67$ (1C-pyrazole ring), $119.45,120.77,127.82,129.65,129.48,130.57$ (1C-pyrazole ring), 136.74, 139.81, 150.68 (1C-pyrazoline ring), 152.91 $(\mathrm{HC}=\mathrm{N})$; $\mathrm{ESI}-\mathrm{MS}(\mathrm{m} / \mathrm{z}):\left[\mathrm{M}^{+}+1\right] 337.15$.

(E)-N-((1-phenyl-3-p-tolyl-1H-pyrazol-4-yl)methylene) benzeneamine Yield: $95 \%$; mp: $222-224^{\circ} \mathrm{C}$; yellow crystals; Anal. calc. for $\mathrm{C}_{23} \mathrm{H}_{19} \mathrm{~N}_{3}$ : C 81.87\%, H 5.68\%, N 12.45\%; found: C 81.90\%, H 5.70\%, N 12.40\%; IR V $\max \left(\mathrm{cm}^{-1}\right): 1624$ $(\mathrm{C}=\mathrm{N}), 3025(\mathrm{CH}-\mathrm{Ar}){ }^{1} \mathrm{H}-\mathrm{NMR}\left(\mathrm{CDCl}_{3}\right) \delta(\mathrm{ppm}): 2.377(\mathrm{~s}, 3 \mathrm{H}$, $\left.\mathrm{CH}_{3}\right), 6.676-7.028(\mathrm{~m}, 5 \mathrm{H}, \mathrm{Ar}-\mathrm{H}), 7.115-7.267(\mathrm{~m}, 2 \mathrm{H}, \mathrm{Ar}-\mathrm{H})$, 7.301-7.397 (m, 2H, Ar-H), 7.413-7.533 (m, 5H, Ar-H), $8.110(\mathrm{~s}, 1 \mathrm{H}, \mathrm{HC}=\mathrm{N}), 8.473\left(\mathrm{~s}, 1 \mathrm{H}, \mathrm{CH}\right.$, pyrazole ring); ${ }^{13} \mathrm{C}-$ $\operatorname{NMR}\left(\mathrm{CDCl}_{3}\right)$ \&ppm: $21.32\left(\mathrm{CH}_{3}\right), 115.17$ (1C-pyrazole ring), $118.59,119.44,120.22,120.88,123.11,126.02,127.48$, 127.96, 129.28, 129.64, 130.37 (1C-pyrazole ring), 131.18, 131.96, 139.38, 152.04 (1C-pyrazole ring), $152.87(\mathrm{HC}=\mathrm{N})$; $\mathrm{ESI}-\mathrm{MS}(\mathrm{m} / \mathrm{z}):\left[\mathrm{M}^{+}+1\right] 337.18$.

(E)-3-methyl-N-((1-phenyl-3-p-tolyl-1H-pyrazol-4-yl) methylene)benzeneamine Yield: $95 \%$; $\mathrm{mp}: 228-230{ }^{\circ} \mathrm{C}$; brown crystals; Anal. calc. for $\mathrm{C}_{24} \mathrm{H}_{21} \mathrm{~N}_{3}: \mathrm{C} 82.02 \%, \mathrm{H}$ $6.02 \%$, N 11.96\%; found: C 82.10\%, H 6.00\%, N 11.92\%;
IR v $\max \left(\mathrm{cm}^{-1}\right): 1627(\mathrm{C}=\mathrm{N}), 3025(\mathrm{CH}-\mathrm{Ar}) ;{ }^{1} \mathrm{H}-\mathrm{NMR}\left(\mathrm{CDCl}_{3}\right)$ $\delta(\mathrm{ppm}): 2.298\left(\mathrm{~s}, 3 \mathrm{H}, \mathrm{CH}_{3}\right), 2.318\left(\mathrm{~s}, 3 \mathrm{H}, \mathrm{CH}_{3}\right), 6.666-6.937$ $(\mathrm{m}, 5 \mathrm{H}, \mathrm{Ar}-\mathrm{H}), 7.010-7.107(\mathrm{~m}, 2 \mathrm{H}, \mathrm{Ar}-\mathrm{H}), 7.204-7.389$ $(\mathrm{m}, 2 \mathrm{H}, \mathrm{Ar}-\mathrm{H}), 7.414(\mathrm{~d}, 1 \mathrm{H}, \mathrm{Ar}-\mathrm{H}), 7.473-7.597(\mathrm{~m}, 3 \mathrm{H}$, $\mathrm{Ar}-\mathrm{H}), 8.205(\mathrm{~s}, 1 \mathrm{H}, \mathrm{HC}=\mathrm{N}), 8.309(\mathrm{~s}, 1 \mathrm{H}, \mathrm{CH}$, pyrazole ring); ${ }^{13} \mathrm{C}-\mathrm{NMR}\left(\mathrm{CDCl}_{3}\right)$ Sppm: $21.02\left(\mathrm{CH}_{3}\right), 21.92\left(\mathrm{CH}_{3}\right), 114.29$ (1C-pyrazole ring), 118.61, 119.53, 120.29, 120.73, 123.54, 126.74, 127.78, 127.76, 129.49, 129.92, 130.44 (1C-pyrazole ring), 131.35, 131.76, 139.74, 152.54 (1C-pyrazole ring), $153.32(\mathrm{HC}=\mathrm{N})$; $\mathrm{ESI}-\mathrm{MS}(\mathrm{m} / \mathrm{z}):\left[\mathrm{M}^{+}+1\right] 351.19$.

(E)-4-methyl-N-((1-phenyl-3-p-tolyl-1H-pyrazol-4-yl) methylene)benzeneamine Yield: $95 \%$; $\mathrm{mp}: 240-242{ }^{\circ} \mathrm{C}$; white crystals; Anal. calc. for $\mathrm{C}_{24} \mathrm{H}_{21} \mathrm{~N}_{3}: \mathrm{C} 82.02 \%, \mathrm{H}$ 6.02\%, N 11.96\%; found: C 82.05\%, H 5.99\%, N 12.01\%; IR $\mathrm{v}_{\max }\left(\mathrm{cm}^{-1}\right): 16120(\mathrm{C}=\mathrm{N}), 3025(\mathrm{CH}-\mathrm{Ar}) ;{ }^{1} \mathrm{H}-\mathrm{NMR}\left(\mathrm{CDCl}_{3}\right)$ $\delta(\mathrm{ppm}): 2.328\left(\mathrm{~s}, 3 \mathrm{H}, \mathrm{CH}_{3}\right), 2.359\left(\mathrm{~s}, 3 \mathrm{H}, \mathrm{CH}_{3}\right), 6.676-6.793$ (m, 5H, Ar-H), 6.877-7.195 (m, 2H, Ar-H), 7.217-7.292 (m, $2 \mathrm{H}, \mathrm{Ar}-\mathrm{H}), 7.325-7.453(\mathrm{~m}, 2 \mathrm{H}, \mathrm{Ar}-\mathrm{H}), 8.490-7.527(\mathrm{~m}, 2 \mathrm{H}$, $\mathrm{Ar}-\mathrm{H}), 8.188(\mathrm{~s}, 1 \mathrm{H}, \mathrm{HC}=\mathrm{N}), 8.389(\mathrm{~s}, 1 \mathrm{H}, \mathrm{CH}$, pyrazole ring); ${ }^{13} \mathrm{C}-\mathrm{NMR}\left(\mathrm{CDCl}_{3}\right)$ \&ppm: $21.59\left(\mathrm{CH}_{3}\right), 22.10\left(\mathrm{CH}_{3}\right), 116.01$ (1C-pyrazole ring), 118.33, 119.21, 120.54, 120.38, 123.74, 126.57, 127.89, 127.83, 129.65, 129.09, 130.23 (1C-pyrazole ring), 131.58, 131.67, 139.78, 152.68 (1C-pyrazole ring), $152.99(\mathrm{HC}=\mathrm{N})$; ESI-MS(m/z): $\left[\mathrm{M}^{+}+1\right] 351.18$.

(E)-N-((3-(4-methoxyphenyl)-1-phenyl-1H-pyrazol-4-yl)methylene)benzeneamine Yield: 95\%; mp: 236$238{ }^{\circ} \mathrm{C}$; white crystals; Anal. calc. for $\mathrm{C}_{23} \mathrm{H}_{19} \mathrm{~N}_{3} \mathrm{O}$ : C 78.16\%, H 5.42\%, N 11.89\%; found: C 78.10\%, H 5.39\%, N 11.91\%; IR $v_{\max }\left(\mathrm{cm}^{-1}\right): 1621(\mathrm{C}=\mathrm{N}), 3025(\mathrm{CH}-\mathrm{Ar}){ }^{1} \mathrm{H}-\mathrm{NMR}\left(\mathrm{CDCl}_{3}\right)$ $\delta(\mathrm{ppm}): 3.781\left(\mathrm{~s}, 3 \mathrm{H}, \mathrm{OCH}_{3}\right), 6.685-7.022(\mathrm{~m}, 5 \mathrm{H}, \mathrm{Ar}-\mathrm{H})$, 7.105-7.277 (m, 2H, Ar-H), 7.313-7.398 (m, 2H, Ar-H), 7.459-7.593 (m, 5H, Ar-H), $8.221(\mathrm{~s}, 1 \mathrm{H}, \mathrm{HC}=\mathrm{N}), 8.517(\mathrm{~s}$, $1 \mathrm{H}, \mathrm{CH}$, pyrazole ring); ${ }^{13} \mathrm{C}-\mathrm{NMR}\left(\mathrm{CDCl}_{3}\right) \delta \mathrm{ppm}: 21.67\left(\mathrm{CH}_{3}\right)$, $54.19\left(\mathrm{OCH}_{3}\right), 114.39$ (1C-pyrazole ring), 119.27, 120.71, 127.41, 129.12, 129.75, 130.21 (1C-pyrazole ring), 136.58, 139.36, 150.43 (1C-pyrazoline ring), $152.45(\mathrm{HC}=\mathrm{N})$; ESI$\mathrm{MS}(\mathrm{m} / \mathrm{z}):\left[\mathrm{M}^{+}+1\right] 353.14$.

(E)-N-((3-(4-methoxyphenyl)-1-phenyl-1H-pyrazol-4-yl)methylene)-3-methyl benzeneamine Yield: 95\%; mp: $214-216{ }^{\circ} \mathrm{C}$; white crystals; Anal. calc. for $\mathrm{C}_{24} \mathrm{H}_{21} \mathrm{~N}_{3} \mathrm{O}: \mathrm{C} 78.45 \%, \mathrm{H} 5.76 \%, \mathrm{~N} 11.44 \%$; found: C 78.50\%, $\mathrm{H} 5.73 \%, \mathrm{~N} 11.41 \%$; IR $v_{\max }\left(\mathrm{cm}^{-1}\right): 1618(\mathrm{C}=\mathrm{N}), 3025(\mathrm{CH}-$ $\mathrm{Ar}) ;{ }^{1} \mathrm{H}-\mathrm{NMR}\left(\mathrm{CDCl}_{3}\right) \delta(\mathrm{ppm}): 2.319\left(\mathrm{~s}, 3 \mathrm{H}, \mathrm{CH}_{3}\right), 3.758(\mathrm{~s}$, $\left.3 \mathrm{H}, \mathrm{OCH}_{3}\right), 6.670-6.885(\mathrm{~m}, 5 \mathrm{H}, \mathrm{Ar}-\mathrm{H}), 6.935-7.177(\mathrm{~m}$, $2 \mathrm{H}, \mathrm{Ar}-\mathrm{H}), 7.213-7.318(\mathrm{~m}, 2 \mathrm{H}, \mathrm{Ar}-\mathrm{H}), 7.364(\mathrm{~d}, 1 \mathrm{H}, \mathrm{Ar}-\mathrm{H})$, 7.392-7.533 (m, 3H, Ar-H), $8.127(\mathrm{~s}, 1 \mathrm{H}, \mathrm{HC}=\mathrm{N}), 8.314(\mathrm{~s}$, $1 \mathrm{H}, \mathrm{CH}$, pyrazole ring); ${ }^{13} \mathrm{C}-\mathrm{NMR}\left(\mathrm{CDCl}_{3}\right) \delta \mathrm{ppm}: 21.92\left(\mathrm{CH}_{3}\right)$, $55.30\left(\mathrm{OCH}_{3}\right), 114.51$ (1C-pyrazole ring), 119.61, 120.56, 127.53, 129.90, 129.74, 130.22 (1C-pyrazole ring), 136.52, 
139.43, 150.51 (1C-pyrazoline ring), $152.33(\mathrm{HC}=\mathrm{N})$; ESI$\mathrm{MS}(\mathrm{m} / \mathrm{z}):\left[\mathrm{M}^{+}+1\right] 367.15$.

(E)-N-((3-(4-methoxyphenyl)-1-phenyl-1 H-pyrazol-4-yl)methylene)-4-methyl benzeneamine Yield: 95\%; mp: $222-224{ }^{\circ} \mathrm{C}$; white crystals; Anal. calc. for $\mathrm{C}_{24} \mathrm{H}_{21} \mathrm{~N}_{3} \mathrm{O}: \mathrm{C} 78.45 \%, \mathrm{H} 5.76 \%, \mathrm{~N} 11.44 \%$; found: C 78.51\%, $\mathrm{H} 5.78 \%, \mathrm{~N} 11.40 \%$; IR v $v_{\max }\left(\mathrm{cm}^{-1}\right): 1614(\mathrm{C}=\mathrm{N}), 3025(\mathrm{CH}-$ $\mathrm{Ar}) ;{ }^{1} \mathrm{H}-\mathrm{NMR}\left(\mathrm{CDCl}_{3}\right) \delta(\mathrm{ppm}): 2.354\left(\mathrm{~s}, 3 \mathrm{H}, \mathrm{CH}_{3}\right), 3.764(\mathrm{~s}$, $\left.3 \mathrm{H}, \mathrm{OCH}_{3}\right), 6.719-6.888(\mathrm{~m}, 5 \mathrm{H}, \mathrm{Ar}-\mathrm{H}), 6.877-7.012(\mathrm{~m}$, $2 \mathrm{H}, \mathrm{Ar}-\mathrm{H}), 7.089-7.198(\mathrm{~m}, 2 \mathrm{H}, \mathrm{Ar}-\mathrm{H}), 7.225-7.350(\mathrm{~m}, 2 \mathrm{H}$, $\mathrm{Ar}-\mathrm{H}), 7.385-7.473(\mathrm{~m}, 2 \mathrm{H}, \mathrm{Ar}-\mathrm{H}), 8.139(\mathrm{~s}, 1 \mathrm{H}, \mathrm{HC}=\mathrm{N}), 8.320$ (s, $1 \mathrm{H}, \mathrm{CH}$, pyrazole ring); ${ }^{13} \mathrm{C}-\mathrm{NMR}\left(\mathrm{CDCl}_{3}\right) \delta \mathrm{ppm}: 21.00$ $\left(\mathrm{CH}_{3}\right), 55.38\left(\mathrm{OCH}_{3}\right), 114.24$ (1C-pyrazole ring), 119.35, $120.80,127.33,129.55,129.85,130.09$ (1C-pyrazole ring), $136.37,139.87,150.39$ (1C-pyrazoline ring), $152.43(\mathrm{HC}=\mathrm{N})$; $\mathrm{ESI}-\mathrm{MS}(\mathrm{m} / \mathrm{z}):\left[\mathrm{M}^{+}+1\right] 367.18$.

(E)-N-((3-(4-chlorophenyl)-1-phenyl-1H-pyrazol-4-yl) methylene)benzeneamine Yield: $95 \%$; $\mathrm{mp}: 234-236{ }^{\circ} \mathrm{C}$; white crystals; Anal. calc. for $\mathrm{C}_{22} \mathrm{H}_{16} \mathrm{ClN}_{3}$ : $\mathrm{C} 73.84 \%, \mathrm{H}$ 4.51\%, N 11.74\%; found: C 73.81\%, H 4.53\%, N 11.77\%; IR $v_{\max }\left(\mathrm{cm}^{-1}\right): 1622(\mathrm{C}=\mathrm{N}), 3025(\mathrm{CH}-\mathrm{Ar}) ;{ }^{1} \mathrm{H}-\mathrm{NMR}\left(\mathrm{CDCl}_{3}\right)$ $\delta(\mathrm{ppm}): 6.728-6.880(\mathrm{~m}, 5 \mathrm{H}, \mathrm{Ar}-\mathrm{H}), 6.920-7.131(\mathrm{~m}, 2 \mathrm{H}$, Ar-H), 7.159-7.278 (m, 2H, Ar-H), 7.301-7.419 (m, 5H, $\mathrm{Ar}-\mathrm{H}), 8.126(\mathrm{~s}, 1 \mathrm{H}, \mathrm{HC}=\mathrm{N}), 8.330(\mathrm{~s}, 1 \mathrm{H}, \mathrm{CH}$, pyrazole ring); ${ }^{13} \mathrm{C}-\mathrm{NMR}\left(\mathrm{CDCl}_{3}\right)$ Sppm: 115.15 (1C-pyrazole ring), 118.59, $119.44,120.22$, 120.88, 123.11, 126.02, 127.48, 127.96, 129.28, 129.64, 130.27 (1C-pyrazole ring), 131.18, 131.96, 139.38, 152.04 (1C-pyrazole ring), $152.85(\mathrm{HC}=\mathrm{N})$; ESI$\mathrm{MS}(\mathrm{m} / \mathrm{z}):\left[\mathrm{M}^{+}+1\right] 357.12$.

(E)-N-((3-(4-chlorophenyl)-1-phenyl-1H-pyrazol-4-yl) methylene)-3-methyl benzeneamine Yield: 95\%; mp: 220-222 ${ }^{\circ} \mathrm{C}$; yellow crystals; Anal. calc. for $\mathrm{C}_{23} \mathrm{H}_{18} \mathrm{CIN}_{3}: \mathrm{C}$ 74.29\%, H 4.88\%, N 11.30\%; found: C 74.20\%, H 5.01\%, N 11.25\%; IR $v_{\text {max }}\left(\mathrm{cm}^{-1}\right): 1609(\mathrm{C}=\mathrm{N}), 3025(\mathrm{CH}-\mathrm{Ar}) ;{ }^{1} \mathrm{H}-$ $\operatorname{NMR}\left(\mathrm{CDCl}_{3}\right) \delta(\mathrm{ppm}): 2.336\left(\mathrm{~s}, 3 \mathrm{H}, \mathrm{CH}_{3}\right), 6.663-6.829(\mathrm{~m}$, 5H, Ar-H), 6.952-7.067 (m, 2H, Ar-H), 7.119-7.209 (m, $2 \mathrm{H}, \mathrm{Ar}-\mathrm{H}), 7.333(\mathrm{~d}, 1 \mathrm{H}, \mathrm{Ar}-\mathrm{H}), 7.421-7.505(\mathrm{~m}, 3 \mathrm{H}, \mathrm{Ar}-\mathrm{H})$, $8.109(\mathrm{~s}, 1 \mathrm{H}, \mathrm{HC}=\mathrm{N}), 8.382\left(\mathrm{~s}, 1 \mathrm{H}, \mathrm{CH}\right.$, pyrazole ring); ${ }^{13} \mathrm{C}-$ NMR $\left(\mathrm{CDCl}_{3}\right) \delta p p m: 22.00\left(\mathrm{CH}_{3}\right), 115.23$ (1C-pyrazole ring), $118.18,119.62$, 120.53, 120.74, 123.56, 126.68, 127.34, 127.76, 129.74, 129.17, 130.47 (1C-pyrazole ring), 131.35, $131.71,139.52,152.45$ (1C-pyrazole ring), $152.58(\mathrm{HC}=\mathrm{N})$; $\mathrm{ESI}-\mathrm{MS}(\mathrm{m} / \mathrm{z}):\left[\mathrm{M}^{+}+1\right] 371.15$.

(E)-N-((3-(4-chlorophenyl)-1-phenyl-1H-pyrazol-4-yl) methylene)-4-methyl benzeneamine Yield: 95\%; mp: 225-227 ${ }^{\circ} \mathrm{C}$; white crystals; Anal. calc. for $\mathrm{C}_{23} \mathrm{H}_{18} \mathrm{CIN}_{3}$ : C 74.29\%, H 4.88\%, N 11.30\%; found: C 74.32\%, H 5.02\%, $\mathrm{N} 11.26 \%$; IR v $v_{\max }\left(\mathrm{cm}^{-1}\right)$ : $1610(\mathrm{C}=\mathrm{N}), 3025(\mathrm{CH}-\mathrm{Ar}) ;{ }^{1} \mathrm{H}-$ NMR $\left(\mathrm{CDCl}_{3}\right) \delta(\mathrm{ppm}): 2.322\left(\mathrm{~s}, 3 \mathrm{H}, \mathrm{CH}_{3}\right), 6.735-7.110(\mathrm{~m}$,
5H, Ar-H), 7.172-7.237 (m, 2H, Ar-H), 7.257-7.318 (m, $2 \mathrm{H}, \mathrm{Ar}-\mathrm{H}), 7.352-7.418(\mathrm{~m}, 2 \mathrm{H}, \mathrm{Ar}-\mathrm{H}), 7.452-7.594(\mathrm{~m}$, $2 \mathrm{H}, \mathrm{Ar}-\mathrm{H}), 8.135(\mathrm{~s}, 1 \mathrm{H}, \mathrm{HC}=\mathrm{N}), 8.310(\mathrm{~s}, 1 \mathrm{H}, \mathrm{CH}$, pyrazole ring): ${ }^{13} \mathrm{C}-\mathrm{NMR}\left(\mathrm{CDCl}_{3}\right) \delta$ ppm: $22.13\left(\mathrm{CH}_{3}\right), 115.85$ (1C-pyrazole ring), 118.78, 119.54, 120.35, 120.77, 123.76, 126.98, $127.88,127.65,129.278,129.86,130.54$ (1C-pyrazole ring), 131.57, 131.56, 139.53, 152.84 (1C-pyrazole ring), 152.61 $(\mathrm{HC}=\mathrm{N}) ; \mathrm{ESI}-\mathrm{MS}(\mathrm{m} / \mathrm{z}):\left[\mathrm{M}^{+}+1\right] 371.14$.

(E)-N-((3-(4-bromophenyl)-1-phenyl-1H-pyrazol-4-yl) methylene)benzeneamine Yield: $95 \%$; mp: $234-236{ }^{\circ} \mathrm{C}$; yellow crystals; Anal. calc. for $\mathrm{C}_{22} \mathrm{H}_{16} \mathrm{BrN}_{3}: \mathrm{C} 65.68 \%, \mathrm{H}$ 4.01\%, N 10.45\%; found: C 65.70\%, H 3.98\%, N 10.50\%; IR $v_{\text {max }}\left(\mathrm{cm}^{-1}\right)$ : $1623(\mathrm{C}=\mathrm{N}), 3025(\mathrm{CH}-\mathrm{Ar}) ;{ }^{1} \mathrm{H}-\mathrm{NMR}\left(\mathrm{CDCl}_{3}\right)$ $\delta(\mathrm{ppm}): 6.683-6.788(\mathrm{~m}, 5 \mathrm{H}, \mathrm{Ar}-\mathrm{H}), 6.935-7.055(\mathrm{~m}, 2 \mathrm{H}$, Ar-H), 7.118-7.217 (m, 2H, Ar-H), 7.293-7.411 (m, 5H, $\mathrm{Ar}-\mathrm{H}), 8.177(\mathrm{~s}, 1 \mathrm{H}, \mathrm{HC}=\mathrm{N}), 8.319(\mathrm{~s}, 1 \mathrm{H}, \mathrm{CH}$, pyrazole ring); ${ }^{13} \mathrm{C}-\mathrm{NMR}\left(\mathrm{CDCl}_{3}\right)$ Sppm: 115.18 (1C-pyrazole ring), 118.59, $119.44,120.22,123.11,126.02,127.42,129.64,130.39$ (1C-pyrazole ring), 131.96, 139.38, 152.04 (1C-pyrazole ring), $152.82(\mathrm{HC}=\mathrm{N})$; $\mathrm{ESI}-\mathrm{MS}(\mathrm{m} / \mathrm{z}):\left[\mathrm{M}^{+}+1\right] 401.07$.

(E)-N-((3-(4-bromophenyl)-1-phenyl-1 H-pyrazol-4-yl) methylene)-3-methyl benzeneamine Yield: 95\%; mp: 224-226 ${ }^{\circ} \mathrm{C}$; yellow crystals; Anal. calc. for $\mathrm{C}_{23} \mathrm{H}_{18} \mathrm{BrN}_{3}$ : C $66.36 \%, \mathrm{H} 4.36 \%$, N 10.09\%; found: C $66.51 \%, \mathrm{H} 4.30 \%$, $\mathrm{N} \mathrm{10.10 \% ;} \mathrm{IR} \mathrm{v} v_{\max }\left(\mathrm{cm}^{-1}\right): 1625(\mathrm{C}=\mathrm{N}), 3025(\mathrm{CH}-\mathrm{Ar}) ;{ }^{1} \mathrm{H}-$ $\operatorname{NMR}\left(\mathrm{CDCl}_{3}\right) \delta(\mathrm{ppm}): 2.290\left(\mathrm{~s}, 3 \mathrm{H}, \mathrm{CH}_{3}\right), 6.717-6.914(\mathrm{~m}$, $5 \mathrm{H}, \mathrm{Ar}-\mathrm{H}), 6.987-7.094(\mathrm{~m}, 2 \mathrm{H}, \mathrm{Ar}-\mathrm{H}), 7.145-7.256(\mathrm{~m}$, $2 \mathrm{H}, \mathrm{Ar}-\mathrm{H}), 7.332(\mathrm{~d}, 1 \mathrm{H}, \mathrm{Ar}-\mathrm{H}), 7.377-7.455(\mathrm{~m}, 3 \mathrm{H}, \mathrm{Ar}-\mathrm{H})$, $8.201(\mathrm{~s}, 1 \mathrm{H}, \mathrm{HC}=\mathrm{N}), 8.355\left(\mathrm{~s}, 1 \mathrm{H}, \mathrm{CH}\right.$, pyrazole ring); ${ }^{13} \mathrm{C}-$ NMR $\left(\mathrm{CDCl}_{3}\right) \delta$ ppm: $21.40\left(\mathrm{CH}_{3}\right), 114.31$ (1C-pyrazole ring), $119.82,120.77,127.67,128.28,129.37,129.37,130.73$ (1C-pyrazole ring), 135.43, 150.51 (1C-pyrazole ring), $151.09(\mathrm{HC}=\mathrm{N}) ; \mathrm{ESI}-\mathrm{MS}(\mathrm{m} / \mathrm{z}):\left[\mathrm{M}^{+}+1\right] 415.08$.

(E)-N-((3-(4-bromophenyl)-1-phenyl-1 H-pyrazol-4-yl) methylene)-4-methyl benzeneamine Yield: 95\%; mp: 230-232 ${ }^{\circ} \mathrm{C}$; white crystals; Anal. calc. for $\mathrm{C}_{23} \mathrm{H}_{18} \mathrm{BrN}_{3}: \mathrm{C}$ $66.36 \%, \mathrm{H}$ 4.36\%, N 10.09\%; found: C 66.40\%, H 4.30\%, $\mathrm{N} 10.12 \%$; IR v $v_{\max }\left(\mathrm{cm}^{-1}\right): 1616(\mathrm{C}=\mathrm{N}), 3027(\mathrm{CH}-\mathrm{Ar}) ;{ }^{1} \mathrm{H}-$ $\operatorname{NMR}\left(\mathrm{CDCl}_{3}\right) \delta(\mathrm{ppm}): 2.329\left(\mathrm{~s}, 3 \mathrm{H}, \mathrm{CH}_{3}\right), 6.671-6.840(\mathrm{~m}$, $5 \mathrm{H}, \mathrm{Ar}-\mathrm{H}), 6.932-7.083(\mathrm{~m}, 2 \mathrm{H}, \mathrm{Ar}-\mathrm{H}), 7.153-7.228(\mathrm{~m}$, $2 \mathrm{H}, \mathrm{Ar}-\mathrm{H}), 7.295-7.372(\mathrm{~m}, 2 \mathrm{H}, \mathrm{Ar}-\mathrm{H}), 7.399-7.512(\mathrm{~m}, 2 \mathrm{H}$, $\mathrm{Ar}-\mathrm{H}), 8.172(\mathrm{~s}, 1 \mathrm{H}, \mathrm{HC}=\mathrm{N}), 8.359(\mathrm{~s}, 1 \mathrm{H}, \mathrm{CH}$, pyrazole ring); ${ }^{13} \mathrm{C}-\mathrm{NMR}\left(\mathrm{CDCl}_{3}\right)$ \&ppm: $20.99\left(\mathrm{CH}_{3}\right), 115.02$ (1C-pyrazole ring), 119.42, 120.75, 127.39, 128.97, 129.60, 129.85, 130.07 (1C-pyrazole ring), 135.03, 150.02 (1C-pyrazole ring),151.71 $(\mathrm{HC}=\mathrm{N})$; $\mathrm{ESI}-\mathrm{MS}(\mathrm{m} / \mathrm{z}):\left[\mathrm{M}^{+}+1\right] 415.09$. 


\subsection{Antimicrobial Screening}

Screening of the antimicrobial therapeutic effect of the synthesized compounds was carried out employing the disc diffusion method. The stock solution of the test compounds was prepared by dissolving one $\mathrm{mg}$ of each compound (1-15) to the $100 \mathrm{~mL}$ of dimethysulphoxide (DMSO). The microbes [S. aureus (ATCC-25923), S. epidermidis (ATCC-29887), E. coli (ATCC-25922), P. mirabilis (ATCC-25933) were sub-cultured in nutrient agar media, following by the McFarland Protocol and transferred to the agar plate. Now the $5 \mathrm{~mm}$ paper discs were prepared and dipped to the test solution and placed to the agar plate to observe the zone of inhibition $(\mathrm{mm})$ followed by incubation. Minimum inhibitory concentration (MIC) was also estimated by macro dilution to understand the smallest concentration of the test compounds to inhibit the growth of microorganism. For estimation of MIC, serial dilutions were made for all the test compounds to the final concentration 400, 200, 100, 50, 12.5, 6.25 and $3.125 \mu \mathrm{g} / \mathrm{ml}$. Ciprofloxacin and DMSO were used as positive and negative control in the study [20].

\subsection{MTT assay}

The enzyme succinate dehydrogenase reduces 3-(4,5-Dimethylthiazol-2-yl)-2,5-diphenyl tetrazolium bromide (MTT) in the mitochondria of the living cells and produces formazon crystal that can be measured spectrophotometrically. To estimate the percent viability of the cells MTT is widely used. Human hepatocellular carcinoma cell line (HepG2) was used to assess the percent viability of cells, Ciprofloxacin was used as a reference drug in the experiment. All the prepared compounds and the Reference drug tested on the sub-confluent population of HepG2 cells with a concentration range 3.125-100 $\mu \mathrm{M}$, and percent viability of cells was observed on $48 \mathrm{~h}$ incubation and reported in Fig. 3.

\section{Conclusion}

A series of fifteen pyrazole derivatives (1-15), structurally elucidated, was screened for antimicrobial therapeutic effect followed by percent viability of the cells. The antimicrobial therapeutic potential was measured in terms of zone of inhibition and MIC. The antimicrobial screening findings portrayed that the potential in three states-significant, moderate and less significant. The compounds 3, 4, 7-14 were possessed significant antimicrobial therapeutic effect against all microorganisms, the compounds $5,6,15$, possessed moderate, while the compound 1 was found less significant. The percent viability of the cells at concentrations $3.125 \mu \mathrm{M}$ and $100 \mu \mathrm{M}$ were observed in the range $91-96 \%$ and $70-75 \%$ respectively.

Acknowledgements The above research work was supported by the Dean of College of Medicine, Al-Dawadmi, Shaqra University kingdom of Saudi Arabia and University Grant Commission Govt. of India (F40-65(C/M)/1009(SA-III/MANF).

\section{Compliance with ethical standards}

Conflict of interest The authors have no conflict of interests

\section{References}

1. Babu KR, Eeshwaraiah B, Aravind D, Harshadas MM, Rallabaldi MR, Apurba B, Rakeshwar B (2008) Synthesis of quinoline analogs: search for antimalarial agents. Monatsh Chem 139:179181. https://doi.org/10.1007/s00706-007-0772-5

2. Kulandaivelu U, Padmini VG, Suneetha K, Shireesha B, Vidyasagar JV, Rao TR, Jayaveera KN, Basu A, Jayaprakash V (2011) Synthesis, antimicrobial and anticancer activity of new thiosemicarbazone derivatives. Arch Pharm 344:84-90. https://doi.org/10.1002/ ardp.201000201

3. Naim MJ, Alam O, Nawaz F, Alam MJ, Alam P (2016) Current status of pyrazole and its biological activities. J Pharm Bioallied Sci 8:2-17. https://doi.org/10.4103/0975-7406.171694

4. Chandrakantha B, Isloor AM, Shetty P, Shetty P, Isloor S, Malladi S, Fun HK (2012) Synthesis, characterization and antimicrobial activity of novel ethyl 1-(N-substituted)-5-phenyl-1 H-pyrazole4-carboxylate derivatives. Med Chem Res 21:2702-2708. https ://doi.org/10.1007/s00044-011-9796-9

5. Bekhit AA, Saudi MN, Hassan AMM, Fahmy SM, Ibrahim TM, Ghareeb D, El-Seidy AM, Nasralla SN, Bekhit AEA (2019) Synthesis, in silico experiments and biological evaluation of 1,3,4-trisubstituted pyrazole derivatives as antimalarial agents. Eur J Med Chem 163:353-366. https://doi.org/10.1016/j.ejmec h.2018.11.067

6. Shi JB, Tang WJ, Qi XB, Li R, Liu XH (2015) Novel pyrazole-5-carboxamide and pyrazole-pyrimidine derivatives: synthesis and anticancer activity. Eur J Med Chem 90:889-896. https://doi. org/10.1016/j.ejmech.2014.12.013

7. Viveka S, Dinesha, Shama P, Gundibasapp-Nagaraja K, Ballav S, Kerkar S (2015) Design and synthesis of some new pyrazolylpyrazolines as potential anti-inflammatory, analgesic and antibacterial agents. Eur J Med Chem 101:442-451. https://doi. org/10.1016/j.ejmech.2015.07.002

8. Abdel-Aziz M, Abuo-Rahma GEA, Hassan A (2009) Synthesis of novel pyrazole derivatives and evaluation of their antidepressant and anticonvulsant activities. Eur J Med Chem 44:34803487. https://doi.org/10.1016/j.ejmech.2009.01.032

9. Harit $T$, Malek F, Bali BE, Khan A, Dalvandi K, Marasini Bishnu P, Noreen S, Malik R, Khan S, Choudhary MI (2012) Synthesis and enzyme inhibitory activities of some new pyrazole-based heterocyclic compounds. Med Chem Res 21:2772. https://doi. org/10.1007/s00044-011-9804-0

10. Kumar RS, Arif IA, Ahamed A, Idhayadhulla A (2016) Antiinflammatory and antimicrobial activities of novel pyrazole analogues. Saudi J Biol Sci 23:614-620. https://doi.org/10.1016/j. sjbs.2015.07.005

11. Malvar DC, Ferreira D, Teixeira R, Castro AD, Raphael C, Ligia Freitas CC, Antonio C, Elson F, Iziara F, Mafra J, Souza G, Vanderlinde F (2013) Antinociceptive, anti-inflammatory and antipyretic 
effects of 1.5-diphenyl-1H-Pyrazole-3-carbohydrazide, a new heterocyclic pyrazole derivative. Life Sciences. 95:81-88. https ://doi.org/10.1016/j.lfs.2013.12.005

12. Vijesh AM, Isloor AM, Shetty P, Sundershan S, Fun HK (2013) New pyrazole derivatives containing 1,2,4-triazoles and benzoxazoles as potent antimicrobial and analgesic agents. Eur J Med Chem 62:410-415. https://doi.org/10.1016/j.ejmech.2012.12.057

13. Sridhar R, Perumal PT, Etti S, Shanmugam G, Ponnuswamy MN, Prabavathy VR, Mathivanan N (2004) Design, synthesis and anti-microbial activity of $1 \mathrm{H}$-pyrazole carboxylates. Bioorg Med Chem Lett 14:6035-6040. https://doi.org/10.1016/j. bmcl.2004.09.066

14. Bebernitz GR, Argentieri G, Battle B, Brennan C, Balkan B, Burkey BF, Eckhardt M, Gao J, Kapa P, Strohschein RJ, Schuster HF, Wilson M, Xu DD (2001) The effect of 1,3-diaryl-[1H]-pyrazole4-acetamides on glucose utilization in ob/ob mice. J Med Chem 44:2601-2611. https://doi.org/10.1021/jm010032c

15. El-Sabbagh OI, Baraka MM, Ibrahim SM, Pannecouque C, Andrei G, Snoeck R, Balzarini J, Rashad AA (2009) Synthesis and antiviral activity of new pyrazole and thiazole derivatives. Eur J Med Chem 44:3746-3753. https://doi.org/10.1016/j.ejmec h.2009.03.038

16. Nitulescu GM, Draghici C, Olaru OT (2013) New potential antitumor pyrazole derivatives: synthesis and cytotoxic evaluation.
Int J Mol Sci 14(11):21805-21818. https://doi.org/10.3390/ijms1 41121805

17. Kajal A, Bala S, Kamboj S, Sharma N, Saini V (2013) Schiff bases: A versatile pharmacophore. J Catal 1:1-15. https://doi. org/10.1155/2013/893512

18. Arshad M, Bhat AR, Hoi KK, Choi I, Athar F (2017) Synthesis, characterization and antibacterial screening of some novel 1,2,4-triazine derivatives. Chin Chem Lett 28:1559-1565. https ://doi.org/10.1016/j.cclet.2016.12.037

19. Arshad, M., Bhat, A. R., Pokharel, S., Lee, E. J., Athar, F., Choi, I., European Journal of Medicinal Chemistry. (2014) Synthesis, characterization and anticancer screening of some novel piperonyl-tetrazole derivatives. 71: 229-236. https://doi.org/10.1016/j. ejmech.2013.11.008

20. Mosmann, T., J. Immunol. Methods. (1983) Rapid colorimetric assay for cellular growth and survival: Application to proliferation and cytotoxicity assays. 65: 55. https://doi. org/10.1016/0022-1759(83)90303-4

Publisher's Note Springer Nature remains neutral with regard to jurisdictional claims in published maps and institutional affiliations. 